\title{
Declining trends in student performance in lower secondary education
}

\author{
Lindy A. Wijsman ${ }^{1}$ • Matthijs J. Warrens ${ }^{2}$ • \\ Nadira $\mathrm{Saab}^{3}$ • Jan H. van Driel ${ }^{3}$. \\ P. Michiel Westenberg ${ }^{1}$
}

Received: 5 June 2015 / Revised: 18 November 2015 / Accepted: 23 November 2015 /

Published online: 18 December 2015

(C) The Author(s) 2015. This article is published with open access at Springerlink.com

\begin{abstract}
Student performance is related to motivation to learn. As motivation generally declines during lower secondary education, one might expect performance to decline as well during this period. Though, until now, it has been unclear whether this pattern exists. In the present study, we examined student performance during the early years of secondary education from a developmental perspective. Participants were 1544 Dutch secondary school students across three grades (grades 7 to 9). To investigate student performance trends, we analysed report card grades by using hierarchical linear modelling with two levels (level 1, time point; level 2, student). Potential moderators to be examined were (1) gender, (2) school type and (3) initial level. A linear decline in report card grades from grade 7 to 9 was found for boys and girls, in all school types, and regardless of initial level. Two variables moderated the steepness of the decline: school type and initial level. Gender and school type had a main effect on performance level. The same pattern was observed for the subset of 'core subjects'—Dutch, English and mathematics. Motivational and cognitive factors that may explain the performance decline are discussed.
\end{abstract}

Keywords Student performance trends $\cdot$ Motivation development $\cdot$ Adolescence $\cdot$ Report card grades $\cdot$ Secondary education

Student performance in lower secondary education is related to motivation to learn at school. Across various empirical studies, a clear pattern emerges: If a student is more motivated to

Lindy A. Wijsman

1.a.wijsman@fsw.leidenuniv.nl

1 Institute of Psychology, Unit Developmental and Educational Psychology, Leiden University, Leiden, Netherlands

2 GION, University of Groningen, Groningen, Netherlands

3 ICLON, Leiden University, Leiden, Netherlands 
learn, he or she performs better in school (e.g. Guay and Vallerand 1997; Pintrich and de Groot 1990; Robbins et al. 2004). Notably, a consistent finding in research on academic motivation is that motivation tends to decline after the transition from primary to secondary education (Eccles et al. 1991; Gottfried et al. 2001; Peetsma et al. 2005). This decline in academic motivation occurs most consistently during early adolescence, until 15 or 16 years of age (Gillet et al. 2012; Gottfried et al. 2001). Given the interdependence of academic motivation and student performance, one might expect performance to decline as well during the early years of secondary education. However, it is unclear whether performance level decreases with a similar pattern to motivation. This study is the first to present data on performance development, in terms of report card grades of all subjects.

\section{Age trends in student performance}

To our knowledge, only two studies report on age trends in student performance during the early high school years. Peetsma et al. (2005) reported a general decline in student performance in a cross-sectional study of 12- to 16-year-olds across four countries: the Netherlands, Switzerland, Czech Republic and eastern parts of Germany. Student performance was assessed using report card grades in mathematics and the mother tongue on the last report card of the year. These school grades were made comparable across countries. Mean scores of investment and performance level decreased with increasing age (i.e. three consecutive age cohorts). A limitation of this study with regard to a developmental perspective on performance is that the concepts were investigated in a cross-sectional study. In a longitudinal study, Gottfried et al. (2007) reported a decline in mean levels of math performance during the early high school years. These researchers used percentile grades on a standardized test to compare student performance between the ages of 9 and 17. The percentile grades were norm-referenced and corrected for grade level and age. As the authors described, this performance measure therefore measures 'the relative change in standing and not absolute value in change over time' (Gottfried et al. 2007, p. 319). Moreover, as the results of this study are limited to mathematics, it is unclear whether similar conclusions can be drawn for other subjects. This limitation also holds for the study of Peetsma et al. (2005), which was limited to mathematics and the mother tongue.

The present study reports on changes in performance levels of young adolescents (12 to 15 years) in lower secondary education. Similar to the performance measure used by Peetsma et al. (2005), we used end-of-the-year report card grades and extended this with a longitudinal approach across a 3-year time span and the inclusion of all school subjects. In the Netherlands, level of student performance is determined with grades received for different tests and assignments throughout the school year, which are taken together on a report card. Report card grades therefore reflect the student's performance level for each subject at the end of each school year. At the end of the school year, report card grades determine whether a student is allowed to advance to the next grade. If grades fall below a predetermined level, the student is advised to switch to another school type or retake the same grade. School grades as measures of student performance, therefore, are important determinants of how students' school careers proceed. These measures are common in practice; however, their trends have not been studied thoroughly.

Based on reports of declining trends in motivation (e.g. Eccles et al. 1991; Gottfried et al. 2001; Peetsma et al. 2005), and the interdependence of motivation and performance 
(e.g. Guay and Vallerand 1997; Pintrich and de Groot 1990; Robbins et al. 2004), we expected to observe an overall declining trend in student performance. It is unclear though whether student performance declines for all subjects at a similar pace. For example, Gottfried et al. (2001) found a significant decline in intrinsic motivation for three important academic subjects - math, science and reading — between the ages of 9 and 16 but did not observe a decline in motivation for social studies. Jacobs et al. (2002) observed that task value declined across the domains of mathematics, language and sports, although the extent and rate of decline varied. In the present study, we compared the developmental trend across all subjects with the trend for three subjects-Dutch, English and mathematics. These subjects are considered the three 'core subjects' in the Netherlands, which means that every student in every type of education is expected to obtain sufficient knowledge of and skills in these subjects. The greater importance attached to these subjects may lead to a different performance trend; e.g. the performance decline for these highly valued subjects might be less steep than for performance across all subjects. In the present study, we compared the developmental trend for performance on the core subjects with the trend for overall student performance.

\section{Moderators of development of student performance}

Trends in student performance might be moderated by several factors. A first potential moderating factor in development of performance level is gender. Research has indicated that secondary education girls tend to perform at a higher level than boys (Duckworth and Seligman 2005; Eccles 1987; Fischer et al. 2013; Wigfield and Wagner 2005). For example, Duckworth and Seligman (2005) showed that high school girls obtained higher grades than the boys. This difference was attributed to boys being less self-disciplined in their studies than girls. However, no difference in performance level was found when this was measured using a norm-referenced skills test. Regarding the development of boys' and girls' performance, different patterns have been suggested. On the one hand, Hill and Lynch (1983) argue that during adolescence, gender role expectations intensify, resulting in increased behavioural differences between boys and girls. On the other hand, Jacobs et al. (2002) argue that differences in self-competence and task values between boys and girls converge during adolescence. Watt (2004) found no evidence for either a gender intensification or convergence hypothesis when focusing on mathematics and English self-perceptions, task values and task perceptions. Also, Mok et al. (2014) found that gender did not affect the growth rate of mathematics scores on a vertically equated scale between grades 3,6 and 9. Overall, research into the developmental patterns of adolescent boys' and girls' motivation and performance does not provide a clear hypothesis of performance trends. The present study considers to what extent different performance trends and diverging or converging growth trajectories can be seen amongst boys and girls.

A second potential moderator of student performance development is school type. In the Dutch school system, secondary education consists of different school types or tracks. At the transition from primary to secondary school, on average at the age of 12 , each student is placed in a pre-vocational, senior general secondary or pre-university education track. This is done based on a combination of the primary school teacher's advice and a test score on a national ability test in the domains language and calculation. The only study conducted in the Netherlands on student performance (Dutch and mathematics) at different school types found no specific relation between school type 
and developmental trends in student performance between grades 7 and 9 (Veenstra 1999). In the present study, we explored potential differences in performance development across all school subjects for students at different school types.

A third potential moderator of performance development may be the student's average performance level in seventh grade (the first year after the transition to secondary school). Some students obtain relatively high performance levels and, due to their greater ability or motivation levels, they might maintain their relatively high performance level throughout lower secondary education. The literature offers no guidance in this respect; it is unclear whether high performers maintain this level or whether they are subject to the same decline as the other students in their class. Indeed, due to the regression-to-the-mean effect, high scorers may display a relatively strong decline during this period. In the present study, we investigated whether high performers in grade 7 might follow a different developmental trend from the low to average performers.

In the current study, we examined student performance during the early years of secondary education from a developmental perspective, by analysing report card grades across three grades. Two research questions guided data analysis: (a) Does student performance decline during lower secondary education? and (b) Is this trend moderated by (1) gender, (2) school type or (3) initial level?

\section{Method}

\section{Participants}

The data for the current study consisted of the end-of-the-year report card grades of 1544 students who started secondary school in 2010, and for whom data was available from grade 7 to 9. The students were in schools which are part of a network of the Leiden University Graduate School of Teaching, in which collaboration is focused on teacher education. The participating group of students is a cross section of the Dutch secondary school population, as it includes students (a) from all three school types (see below), (b) from rural, suburban and urban regions and (c) from different socioeconomic backgrounds. Boys (49\%) and girls were approximately equally represented in the sample.

The students came from all three school type levels, which in the Netherlands means that they were in either the pre-vocational, the senior general secondary or the pre-university school type. These school types are of increasing levels of difficulty. Pre-vocational education prepares for senior vocational education, senior general secondary education prepares for higher professional education, and pre-university education prepares for university. In addition to these three levels, so-called 'combination classes' are provided in grades 7 and 8, which are a combination of pre-vocational and senior general secondary, or of senior general secondary and pre-university education. These combination classes give students the opportunity to experience which school type fits best. Combination classes do not exist in the ninth grade. By that time, all students are assigned to one of the three school types. Table 1 presents the distribution of students across school types in grade 7 (including combination classes) and in grade 9 (no combination classes). Table 1 also shows the changes in school type that were made between grades 7 and 9. It shows that in total, 628 students stayed in the same school type between grades 7 and 9, 371 students changed to a higher-level school type, and 538 students changed to a lower school type. 
Table 1 Crosstab of changes in school types between grades 7 and 9

\begin{tabular}{lccccccc}
\hline Grade 9 & 1 & 2 & 3 & 4 & 5 & Total \\
Grade 7 & & & & & & \\
\hline 1. pre-vocational & 356 & - & 13 & - & - & 369 \\
2. pre-vocational/senior general & 150 & - & 159 & - & 15 & 324 \\
3. senior general & 2 & - & 10 & - & 3 & 15 \\
4. senior general/pre-university & 103 & - & 261 & - & 181 & 545 \\
5. pre-university & 4 & - & 18 & - & 262 & 284 \\
Total & 615 & & 461 & & 461 & 1537
\end{tabular}

Light grey boxes represent students who changed to a higher-level school type (total=371). Middle grey boxes represent students who changed to a lower school type (total=538). Dark grey boxes represent equivalent school types in grades 7 and 8 (total=628). The total number of students adds up to 1537 due to 7 missing scores on school type in grade 7

\section{Procedure}

The participating secondary schools broadly represent the student population in the Netherlands as they included all school types in a mixture of urban and rural regions. Most schools offer a combination of school types; a few schools offer a single school type. Especially in the Dutch context, most schools offer multiple school types under one roof, in order to make sure that students can stay in the same school, even if they have to make a change in school type. We asked all schools in this network for permission to use report card grades of the first 3 years of secondary school of cohort 2010/2011. Nine out of the 13 invited schools participated, and these schools included all school types and were located in different cities and townships.

School performance data were collected from school records. To gather the report card grades, the researcher either went to the schools to derive data on the spot in collaboration with the IT manager, or the school sent the data via email. We only included participants in the analyses for whom we had performance scores of grades 7,8 and 9. Students generally do not repeat a class in the Netherlands but do change school type if necessary. Since most of the participating schools offer multiple school types, also if a student changed school type during these years, he or she could still be included in the study. No information was available about the percentage of students who had left the school, for example because of moving to another city. Anonymity of students in the dataset was guaranteed by ascribing every participant a random number before the data were used in analyses.

\section{Measures}

Student performance was indexed using the end-of-the-year report card grades from the first 3 years of secondary school (grades 7, 8 and 9). Report card grades in the Netherlands range between 1 (extremely poor) and 10 (outstanding): Grades below 6 are considered insufficient (i.e. not passing), whereas a grade of 6 or higher is considered sufficient (i.e. passing). End-ofthe-year subject grades are composed of the grades for all tests that a student takes in a particular school year for that subject. 
To study overall performance trends, we averaged the end-of-the-year report card grades across all school subjects into an overall end-of-the year report card grade. In addition, we created a core subjects grade by taking the average end-of-the-year report card grades for Dutch, English and mathematics.

\section{Analyses}

We analysed developmental performance patterns in grades 7 to 9 using multilevel regression analyses with two levels (Snijders and Bosker 2012). Level 1 consisted of time point within a student, and level 2 was student. First, we tested a model with time as a level 1 indicator of multiple time points (model 1a). Next, we added the moderating variables gender (boys, girls; models $1 \mathrm{~b}$ and $1 \mathrm{c}$ ) and school type in grade 9 (pre-vocational, senior general and preuniversity; models 1d and 1e). School type in grade 9 was chosen as the reference school type because it is considered to have the best predictive value for the school type in higher secondary education. Moreover, the mentioned models 1a to 1e were fitted for both overall performance and performance in the core subjects Dutch, English and mathematics.

In a second model, we added to model 1a the variable change in school type between grades 7 and 9 (up, equal or down; see Table 1). Performance level may be affected by a change in school type: For example, if a student moves from senior general to pre-university education, this might lead to declining report card grades, whereas a move from secondary general to pre-vocational might lead to higher grades. Such changes in report card grades may affect performance trends between grades 7 and 9 . To control for this possibility, we added the variable 'change in school type' in model 2.

In models 1a to 2, fixed and random effects of time were included, while in models $1 \mathrm{~b}$ to 2 , also fixed effects of the group variables were included. In models 1c and 1e, cross-level interactions were added between time and the group variables. Both linear and piecewise linear models were fitted. Piecewise linear models have more parameters and therefore a better fit. For ease of interpretation and because the group trends in the piecewise linear models were very similar to the linear trends, only the results of the linear multilevel models are presented. Descriptive statistics were provided in order to comprehend whether high initial performance causes student performance to develop differently from the general developmental pattern. Data from all 3 years were normally distributed. The level 1 residuals were normally distributed for all multilevel models. Furthermore, for all models, the plots of predicted values versus residuals showed no non-random patterns. We therefore concluded that the assumptions of the multilevel models are reasonably well met.

\section{Results}

Descriptive statistics provided in Table 2 are consistent with the expected decline in student performance in lower secondary education. The average overall mean report card grade for all students dropped from $7.10(S D=0.53)$ in grade 7 to $6.83(S D=0.54)$ in grade 8 and 6.57 $(S D=0.55)$ in grade 9 . This declining trend was observed for the different school types and for boys and girls.

The results of the different models that were tested are shown in Table 3. Model 1a serves as a variance component model, dividing the intercept variance into different variance components at both levels (Hox 2010). From this model, we calculated that $74 \%$ of the 
Table 2 Performance levels in grades 7 to 9

$n \quad$ Performance grade 7 (SD) Performance grade 8 (SD) Performance grade 9 (SD)

\begin{tabular}{lllll}
\hline $\begin{array}{l}\text { School type grade } 9 \\
\text { Pre-vocational }\end{array}$ & 615 & $6.90(0.53)$ & $6.69(0.57)$ & $6.44(0.51)$ \\
Senior general & 464 & $7.01(0.42)$ & $6.70(0.40)$ & $6.46(0.50)$ \\
$\begin{array}{r}\text { Pre-university } \\
\text { Gender }\end{array}$ & 465 & $7.45(0.47)$ & $7.15(0.51)$ & $6.83(0.57)$ \\
Boys & 753 & $7.00(0.51)$ & $6.73(0.50)$ & $6.48(0.51)$ \\
Girls & 791 & $7.20(0.54)$ & $6.93(0.56)$ & $6.65(0.58)$ \\
Total & 1544 & $7.10(0.53)$ & $6.83(0.54)$ & $6.57(0.55)$
\end{tabular}

School type grade 9 was used as the grouping variable for school type. Pre-vocational consists of basic advanced, mixed and theoretical streams; senior general and pre-university also include bilingual variants

variance in report card grade was located at the higher (student) level. This means that $26 \%$ of the variance is located at the first - time point - level. Multilevel analysis was justified, as a high percentage of variance was located at the second level $(74 \%, z=21.27, p<.001)$. Time is a significant predictor of student performance in model 1a $(t(1542)=-39.60, p<.001)$. With every grade (one time point), end-of-the-year report card grades decrease by 0.27 . There is a significant correlation between the intercepts and the slopes of the regression lines of the students $(z=-7.64, p<.001)$. The negative correlation $(r=-.38)$ indicates that students with a relatively high mean report card grade in grade 7 show a relatively fast decline between grades 7 and 9.

\section{Moderator 1: gender}

Model $1 \mathrm{~b}$ tested the potential sex differences in the performance development. The main effect of gender was a significant predictor. This model fitted the data significantly better than model 1a $\left(\chi^{2}=66.12, d f=1, p<.001\right)$. Model 1b shows that on average boys initially score lower than girls (intercept girls $=7.19$, intercept boys=7.00). Model 1c extended the previous model with a cross-level interaction between time and gender. This interaction was non-significant $(t(1550.46)=1.12, p=.26)$. The decline of student performance, therefore, is the same for these two groups over time. Also, model fit did not increase using model $1 \mathrm{c}$, when compared with model $1 \mathrm{~b}\left(\chi^{2}=1.26, d f=1, p=.26\right)$. When compared with model 1a, gender explains $4.8 \%$ of the variance in end-of-theyear report card grades at the student level, which is a moderate effect size (Snijders and Bosker 2012).

\section{Moderator 2: school type}

Model 1d was fitted in order to test whether performance development differs across school types, with gender also taken into account. This model shows that school type is a significant predictor. Model 1d significantly improved model $1 \mathrm{~b}\left(\chi^{2}=339.68, d f=2, p<.001\right)$. Model $1 \mathrm{e}$ extended the latter model through a cross-level interaction between time and school type. This addition increased model fit $\left(\chi^{2}=24.35, d f=2, p<.001\right)$. Model 1e shows that in grade 7 , girls 
Table 3 Multilevel models for performance with gender, school type, and change in school type as predictors

\begin{tabular}{|c|c|c|c|c|c|c|}
\hline & Model 1a & Model 1b & Model 1c & Model 1d & Model 1e & Model 2 \\
\hline & Fixed effects & & & & & \\
\hline Intercept & $7.10(.01)^{* *}$ & $7.19(.02)^{* *}$ & $7.20(.02)^{* *}$ & $7.51(.02)^{* *}$ & $7.55(.02)^{* *}$ & $7.42(.02)^{* *}$ \\
\hline Level 1 time & $-0.27(.01)^{* *}$ & $-0.27(.01)^{* *}$ & $-0.28(.01)^{* *}$ & $-0.27(.01)^{* *}$ & $-0.31(.01)^{* *}$ & $-0.36(.01)^{* *}$ \\
\hline \multicolumn{7}{|l|}{ Level 2} \\
\hline Boys & & $-0.19(.03)^{* *}$ & $-0.21(.03)^{* *}$ & $-0.19(.02)^{* *}$ & $-0.19(.02)^{* *}$ & \\
\hline Boys $*$ time & & & $-0.02(.01)$ & & & \\
\hline Pre-voc. & & & & $-0.47(.03)^{* *}$ & $-0.54(.03)^{* *}$ & \\
\hline Sen. gen. & & & & $-0.43(.03)^{* *}$ & $-0.46(.03)^{* *}$ & \\
\hline Pre-voc. * time & & & & & $0.08(.02)^{* *}$ & \\
\hline Sen. gen. $*$ Time & & & & & $0.04(.02)^{*}$ & \\
\hline Equal & & & & & & $-0.16(.03)^{* *}$ \\
\hline Down & & & & & & $-0.67(.03)^{* *}$ \\
\hline Equal $*$ time & & & & & & $0.08(.01)^{* *}$ \\
\hline \multirow[t]{2}{*}{ Down $*$ time } & & & & & & $0.17(.02)^{* *}$ \\
\hline & Random effects & & & & & \\
\hline$\sigma_{\mathrm{e}}^{2}$ (residual) & $0.08(.003)^{* *}$ & $0.08(.003)^{* *}$ & $0.08(.003)^{* *}$ & $0.08(.003)^{* *}$ & $0.08(.003)^{* *}$ & $0.08(.003)^{* *}$ \\
\hline$\sigma_{\mathrm{u} 0}^{2}$ (intercept) & $0.23(.011)^{* *}$ & $0.22(.010)^{* *}$ & $0.22(.010)^{* *}$ & $0.17(.009)^{* *}$ & $0.17(.009)^{* *}$ & $0.15(.008)^{* *}$ \\
\hline$\sigma_{\mathrm{u} 1}^{2}$ Slope & $0.03(.003)^{* *}$ & $0.03(.003)^{* *}$ & $0.03(.003)^{* *}$ & $0.03(.003)^{* *}$ & $0.03(.003)^{* *}$ & $0.03(.003)^{* *}$ \\
\hline$\sigma_{\text {u0u1 }}^{2}$ Covariance & $-0.03(.004)^{* *}$ & $-0.03(.004)^{* *}$ & $-0.03(.004)^{* *}$ & $-0.03(.004)^{* *}$ & $-0.02(.004)^{* *}$ & $-0.01(.004)^{* *}$ \\
\hline -2LogLikelihood & 5546.21 & 5480.09 & 5478.83 & 5140.41 & 5116.06 & 4993.80 \\
\hline
\end{tabular}

Reference groups are groups with the highest performance level: girls (as compared to boys), pre-university (as compared to the other school types) and changing to a higher school type (as compared to the other change in school type groups). Standard errors are in parentheses. Model $1 \mathrm{a}=$ variance component model, model $1 \mathrm{~b}=$ model $1 \mathrm{a}+$ main effect gender, model $1 \mathrm{c}=$ model $1 \mathrm{~b}+$ interaction effect gender, model $1 \mathrm{~d}=$ model $1 \mathrm{~b} .+$ main effect school type, model $1 \mathrm{e}=$ model $1 \mathrm{~d}+$ interaction effect school type, model $2=$ model $1 \mathrm{a}+$ main and interaction effects change in school type

${ }^{*} p<.05$, two-tailed; $* * p<.001$, two-tailed

in pre-university education (7.55) score highest on average, while boys at pre-vocational education score lowest (6.81). When compared with model 1b, school type explains $24.2 \%$ of the variance in performance at the student level, which is a very substantial effect size. In model 1e, gender and school type together explain $28.7 \%$ of the variance in performance. Thus, the common variance between gender and school type is only $0.3 \%$, which shows that the two predictors are practically independent.

Figure 1 visually represents model 1e, showing the effects of both gender and school type over time. This figure shows no interaction effect of time and gender, thus boys' and girls' performance developed at the same pace between grades. Girls did score higher than boys in all three grades, due to the found main effect. An interaction between time and school type was found, meaning that the developmental pattern was not the same for every school type. In Fig. 1, we see that students in pre-university education perform highest when compared with students in the other school types in all three grades. The expected performance decline was observed for all three school types with 


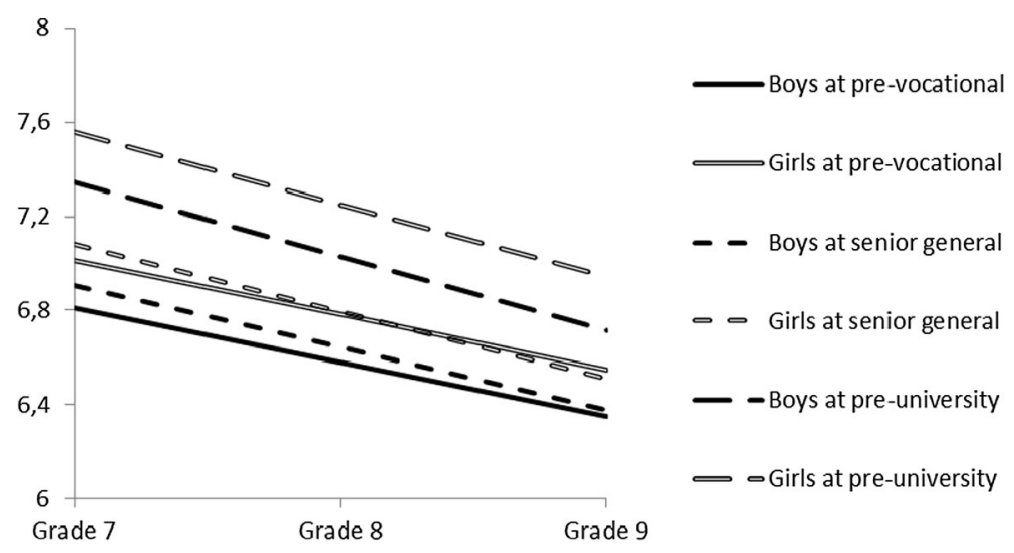

Fig. 1 Performance in grade 7 to 9 of boys and girls at different school types

similar steepness for pre-university and senior general secondary education and a less steep decline for pre-vocational education.

\section{Moderator 3: initial performance level}

The negative correlation $(r=-.38)$ between time and performance level as reported in model $1 \mathrm{a}$ showed that performance of students who start at a higher level generally declines at a faster rate. As a next step, we distinguished the performance development of students who started at a high performance level at the end of grade 7, in order to analyse whether this specific group of students shows a different developmental pattern than students with moderate to low report card grades. In grade 7, 92 students $(6.0 \%)$ have an average report card grade equal to or greater than an 8 . Of these 'high performers', only 19 students $(20.7 \%$; and $1.2 \%$ of the total sample) still performed at that level by the end of grade 9 . These students all are in preuniversity education, and 16 of them are girls. This means that most students who start at a high performance level also show the downward trend.

\section{Performance in the core subjects}

Models 1a to 1e in Table 3 each illustrate downward trends in overall student performance. Similar to these models, models 1a to 1e in Table 4 show performance development in the core subjects. In general, models 1a to $1 \mathrm{e}$ in Table 4 show that performance development in the three core subjects is equal to that over all subjects. The performance level is somewhat lower for the core subjects, but the developmental trend is the same and declines between grades 7 and 9.

From model 1a, we calculated that $68.4 \%$ of the variance in report card grades for the core subjects was located at the student level. This model shows that time was a significant predictor of the mean grade $(t(1540.62)=-28.13, p<.001)$. With every year (one time point), the mean grade for all core subjects taken together decreases by 0.27 . The negative correlation between intercept and slope $(r=-.49)$ indicates that students with a relatively high mean grade in year 1 show a relatively fast decline 
Table 4 Multilevel models for performance in core subjects (Dutch, English and mathematics) with gender and school type as predictors

\begin{tabular}{llllll}
\hline & Model 1a & Model 1b & Model 1c & Model 1d & Model 1e \\
\hline & Fixed effects & & & & \\
Intercept & $6.95(.02)^{* *}$ & $7.09(.02)^{* *}$ & $7.07(.03)^{* *}$ & $7.36(.03)^{* *}$ & $7.45(.03)^{* *}$ \\
Level 1 time & $-0.27(.01)^{* *}$ & $-0.27(.01)^{* *}$ & $-0.25(.01)^{* *}$ & $-0.27(.01)^{* *}$ & $-0.34(.02)^{* *}$ \\
Level 2 & & & & & \\
$\quad$ & & $-0.28(.03)^{* *}$ & $-0.26(.04)^{* *}$ & $-0.28(.03)^{* *}$ & $-0.28(.03)^{* *}$ \\
$\quad$ Boys & & & $-0.02(.02)$ & & \\
$\quad$ Preys * time & & & & $-0.35(.03)^{* *}$ & $-0.50(.04)^{* *}$ \\
$\quad$ Sen. gen. & & & & $-0.45(.04)^{* *}$ & $-0.54(.05)^{* *}$ \\
$\quad$ Pre-voc. $*$ time & & & & & $0.14(.02)^{* *}$ \\
$\quad$ Sen. Gen. * time & & & & & $0.08(.02)^{* *}$ \\
& Random effects & & & & \\
$\sigma_{\mathrm{e}}^{2}$ (residual) & $0.18(.006)^{* *}$ & $0.18(.007)^{* *}$ & $0.18(.007)^{* *}$ & $0.18(.007)^{* *}$ & $0.18(.007)^{* *}$ \\
$\sigma_{\text {u0 } \text { (intercept) }}$ & $0.39(.020)^{* *}$ & $0.37(.020)^{* *}$ & $0.37(.020)^{* *}$ & $0.32(.018)^{* *}$ & $0.32(.018)^{* *}$ \\
$\sigma_{\text {u1 }}^{2}$ Slope & $0.05(.006)^{* *}$ & $0.05(.006)^{* *}$ & $0.05(.006)^{* *}$ & $0.05(.006)^{* *}$ & $0.04(.006)^{* *}$ \\
$\sigma_{\text {u0u1 Covariance }}^{2}$ & $-0.07(.009)^{* *}$ & $-0.07(.009)^{* *}$ & $-0.07(.009)^{* *}$ & $-0.06(.008)^{* *}$ & $-0.06(.008)^{* *}$ \\
-2 LogLikelihood & 8619.74 & 8532.91 & 8531.63 & 8373.45 & 8336.08
\end{tabular}

Reference groups are groups with the highest performance level: girls (as compared to boys), pre-university (as compared to the other school types) and changing to a higher school type (as compared to the other change in school type groups). Standard errors are in parentheses. Model $1 \mathrm{a}=$ variance component model, model $1 \mathrm{~b}=$ model $1 \mathrm{a}+$ main effect gender, model $1 \mathrm{c}=$ model $1 \mathrm{~b}+$ interaction effect gender, model $1 \mathrm{~d}=$ model $1 \mathrm{~b}+$ main effect school type, model $1 \mathrm{e}=$ model $1 \mathrm{~d}+$ interaction effect school type

${ }^{*} p<.05$, two-tailed; $* * p<.001$, two-tailed

between grades 7 and 9 . Model $1 \mathrm{~b}$ shows that on average boys initially score lower than girls (intercept girls $=7.09$, intercept boys=6.82). This model fitted the data significantly better than model $1 \mathrm{a}$, which included only time as a predictor $\left(\chi^{2}=\right.$ 86.83, $d f=1, p<.001)$. Compared with model 1a, gender explains $4.5 \%$ of the variance of the mean grade at the student level. Model 1c was fitted in order to check whether the slopes of boys and girls were equal. This model did not improve the previous model $\left(\chi^{2}=1.28, d f=1, p=.26\right)$, and the cross-level interaction between time and gender was non-significant $(t(1548.36)=-1.13, p=.26)$. Performance development in the core subjects, therefore, is the same for these two groups over time. The main effect of school type is a significant predictor in model $1 \mathrm{~d}$. This model fitted the data better than model $1 \mathrm{~b}\left(\chi^{2}=159.46, d f=2, p<.001\right)$. Cross-level interactions between time and the school types were added in model $1 \mathrm{e}$, which appeared to be significant for both pre-vocational education $(t(1539.32)=6.14, p<.001)$ and senior general secondary education $(t(1538.09)=3.50, p<.001)$. Model $1 \mathrm{e}$ represented the data better than the previous model $\left(\chi^{2}=37.37, d f=2, p<.001\right)$. In model 1e, gender and school type together explain $19.4 \%$ of the variance in performance. Thus, the 
common variance between gender and school type is only $0.1 \%$. Performance development in the separate subjects Dutch, English and mathematics showed similar downward patterns.

\section{Changes in school type}

Finally, we assessed possible effects of changing school type using a multilevel model. Model 2 in Table 3 extends model 1a by including the variable change in school type with the following three categories: students who stayed in an equivalent school type across lower secondary school (equal), students who rose to a higher level school type (up) and students who dropped to a lower level school type (down). Figure 2 is a visual representation of model 2 . The figure shows that there are different intercepts in grade 7. Furthermore, the figure shows downward trends for each group, and a significantly different relation between performance and time for the three groups (interaction between change in school type and time). This declining trend was steepest for the group of students that rose to a higher-level school type, and least steep for those students who dropped to a lower level school type. When we study performance of students who dropped to a lower-level school type, the performance decline was somewhat steeper for students who changed from a combined senior general $/$ preuniversity to a senior general level $\left(M_{\text {performance }}\right.$ grade $7=6.96, M_{\text {performance }}$ grade $9=$ 6.42; performance difference $=-0.54)$, than for students who dropped from a combined senior general/pre-university $\left(M_{\text {performance }}\right.$ grade $7=6.62, M_{\text {performance }}$ grade $9=6.42$; performance difference $=-0.20)$ or a combined pre-vocational/senior-general ( $M_{\text {performance }}$ grade $7=6.60, M_{\text {performance }}$ grade $9=6.43$; performance difference $=-0.17$ ) to a pre-vocational level. Moreover, all groupings dropped to a lower performance level between the seventh and ninth grade, regardless of staying at the same school level or not. Even students who changed to an 'easier' school level still decreased in their performance level.

Fig. 2 Line diagram of performance for students grouped according to change in school type

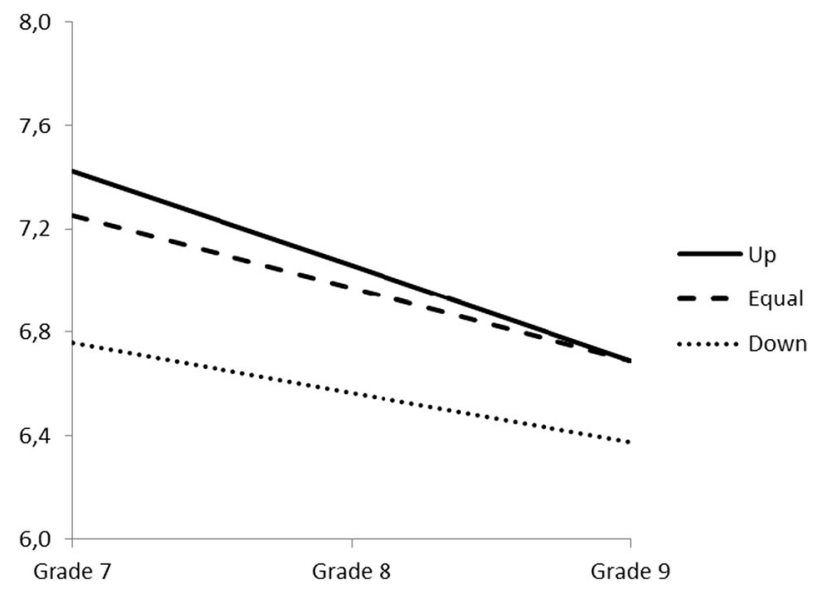




\section{Discussion}

In the present study, we investigated to what extent an overall declining pattern in student performance in lower secondary education was apparent, and to what extent this pattern was moderated by gender, school type and initial performance level. Additionally, the models were also evaluated for performance in the core subjects. The results were as hypothesized and showed a clear linear decline in overall student performance as well as for the core subjects Dutch, English and mathematics. This decline in student performance corresponds with a decline in investment and academic performance in the same age period as reported by Peetsma et al. (2005) and Gottfried et al. (2007). Due to the longitudinal approach and the inclusion of several moderators, the present study provides more detailed and compelling evidence for declining student performance in lower secondary education.

The performance decline was found regardless of the moderators that were distinguished in this study: gender, school type and initial level. These moderators, however, did sometimes affect the performance level itself or the strength of the performance decline. First, boys start at a lower performance level than girls after the transition to secondary education, and their performance subsequently decreases in a pattern similar to that found for girls. This means that performance declines for girls and boys but that girls maintain their relative advantage. A similar developmental pattern for boys and girls is in line with the findings of research by Mok et al. (2014) and Watt (2004), who did not find evidence for a gender intensification or gender convergence hypothesis. Watt (2004) observed an already existing difference between boys and girls at the start of their school career. Research findings regarding differences between boys and girls have been explained by using culture perspectives, stating that boys' culture is less study-oriented than girls' culture in Belgium (van Houtte 2004). In addition, research in America has shown that girls are more selfdisciplined in studying than boys (Duckworth and Seligman 2005).

Second, when we grouped students based on their school type-pre-vocational, senior general and pre-university - we found that students at all school types showed the expected performance decline. At the same time, an interaction between school type and time was found. The results showed that the decrease in performance level is steepest for pre-university students. Pre-university students started with the highest performance level in grade 7 and showed the steepest decline. Nonetheless, by the end of grade 9, students in pre-university education still have the highest performance level. While students in senior general secondary education had higher performance levels than pre-vocational students in grade 7 , by the end of grade 9 both groups have equal performance levels.

Third, the linear decline in student performance was observed regardless of initial performance level. At the same time, performance of students with a high initial level generally declined at a faster rate than performance of students who started at a lower level. In addition, a group of 92 high performers was identified in grade 7, of whom only 19 students were able to maintain this level into the ninth grade. Thus, only very few students are able to maintain a high performance level during lower secondary education.

\section{Explaining the performance decline}

Motivational and cognitive factors may play a role in the observed performance decline. In order to perform well, students need to be motivated to put effort into their schoolwork, and they have to be able to keep up with the increasing cognitive demands as they proceed through secondary school. 
Motivational factors related to performance development We hypothesized the performance decline on the basis of two underlying assumptions: (1) that motivation declines during secondary school and (2) that motivation and student performance are interrelated. The motivation decline is found for various facets of motivation, such as intrinsic motivation (Pintrich and de Groot 1990; Wigfield and Wagner 2005), mastery goal (Shim et al. 2008) and time investment (Peetsma et al. 2005). Therefore, when explaining the performance decline during secondary school, several motivational factors may be important.

A first motivational factor related to the question of putting effort into schoolwork is utility value. This concept describes the perceived usefulness of an academic subject in the present and the future. Usefulness of a school subject for students' lives is not always clear to them. Utility value was found to decline for both boys and girls between grades 7 and 11 in the context of mathematics (Chouinard and Roy 2008; Watt 2004). In the context of the present study, utility value may influence performance. Besides a lack of relevancy of school subjects for students' lives, the Dutch grading system may also be a factor in explaining decreasing utility value. Grading in the Netherlands ranges between 1 and 10, but a 6 is generally sufficient to pass a test and to advance to the next grade. Therefore, there seems to be no reason to invest extra effort to obtain higher grades. This mentality of mediocrity, that is reaching a sufficient result with minimal effort, is currently often discussed in Dutch politics. The Dutch Inspectorate of Education (2014) ascertained that both the intrinsic and the extrinsic motivation of Dutch students were at a low level compared with those in other countries.

Two additional explanations have been offered for the motivational decline in secondary school. First, a misfit between the student and the environment (Eccles et al. 1993) was reported. This so-called stage-environment misfit means that the school environment does not fit the needs of students, leading to friction between what a student wants and the opportunities offered by the school. This friction is linked to negative development of motivation and self-perceptions (Eccles et al. 1993). The second is a shifting relevance of life domains for adolescents (Peetsma 1997, as cited in Peetsma and van der Veen 2011). This means that the value of other life domains, such as social value, becomes larger than the value of school.

Juvonen and Murdock (1995) investigated the social value of putting effort into schoolwork in three age groups. They found that 10- and 12-year-olds were eager to show their teachers and peers that they worked hard, while amongst 14-year-olds, this was not done. The social value of effort changed between these age groups, as the 14-year-olds saw diligence as positive to teacher approval but negative to peer popularity. The age group in Juvonen and Murdock's study is similar to that in our study, and social value may be an important factor in decreasing performance. Students may sometimes fear being downgraded in the peer group, or even being bullied because others think they are showing off. Another reason for adolescents to put less effort into their schoolwork is that they tend to believe that ability is a stable internal trait (Anderman and Maehr 1994).

As a final motivational factor, Duckworth and Seligman (2005) argue that, with regard to performance at school, self-discipline becomes especially important in secondary school. It may be that students lack self-discipline in studying and therefore have a relatively low level of performance. As the school curriculum requires more independence of students when they proceed to higher grades, it is possible that their self-discipline is not strong enough to cope.

Cognitive factor related to performance development Cognitive ability might also be a contributing factor to the observed performance decline. As secondary school proceeds, subject content changes in nature. The ultimate learning goals often contain higher-order skills such as evaluating and creating (Krathwohl 2010), instead of less complex such as remembering and 
understanding. The more complex the skills, the more demanding the cognitive challenge for students. The skills distinguished in Bloom's taxonomy are also used in the assessment of subjects. The assessments, therefore, become cognitively more demanding over the years. In order to be able to master the more difficult cognitive activities, metacognitive skills need to be developed. Metacognitive skills refer to the procedural knowledge necessary to reflect on one's learning activities (van der Stel and Veenman 2010). These skills develop in adolescence, and especially during grades 7 to 9 at about 12 to 15 years of age (van der Stel and Veenman 2010). In addition, neuroscientific research has shown that the frontal cortex is involved in metacognition (FernandezDuque et al. 2000) and this part of the brain continues to develop during adolescence (Steinberg 2005). Therefore, metacognition during the first years of secondary education may not be fully developed yet, making it more difficult for students to keep up with more complex tasks at school.

\section{Implications}

Implications of the present study focus on possible strategies to tackle the performance decline. The proposed motivational and cognitive explaining factors are used to structure these implications. When reasoning from the motivational factor, an intervention focused on strengthening the utility value of school subjects may be helpful. Hulleman et al. (2010) studied an example of such an intervention. In their study, the authors found that a writing intervention that encouraged students to discover how school tasks are connected to their own lives increased utility value perceptions, which in turn predicted increased performance and interest. The effects were strongest for low-scoring students. Second, from a motivational perspective, an intervention could focus on the social value of effort. Such an intervention should focus on peer-interaction, as older students see effort as a negative influence on peer popularity (Juvonen and Murdock 1995). A third intervention from a motivational perspective could focus on increasing self-discipline. In order to increase self-discipline, a focus on strengthening volitional strategies may be in place. Volitional strategies refer to persistence in task focus and effort investment, also in a context that may contain distractions (Boekaerts et al. 2010). An example for strengthening volitional strategies in order to increase students' focus on learning goals is a strategy training in good work habits (Boekaerts and Corno 2005). Additionally, a teacher can model effective strategies (Boekaerts et al. 2010).

Reasoned from the cognitive factor, and the possible lack of metacognitive skills, a training of these skills may help students to better be able to keep up with increasingly difficult subject content. Metacognitive skills training for instance has led to increased mathematics performance on a criterion-referenced test including mathematics problems, and a better attitude towards mathematics in students scoring low on mathematics (Cardelle-Elawar 1992). Training on metacognitive skills and working memory additionally led to improved arithmetic problem solving skills in 8- to 10-year-olds (Cornoldi et al. 2015).

\section{Limitations and recommendations for future research}

The observed performance decline is explained in terms of motivational and cognitive factors. The data set for the present study was derived from regular school records, and these records did not include data on motivation and cognition. In future studies, it would be important to include the assessment of these factors and to investigate their relationship with the performance decline. Our recommendation is to include motivational and cognitive measures such as social value, utility value, self-discipline and metacognitive skills in future research. 
This study specifically studied report card grades as a performance measure, because these are the performance measures which in schools are used to determine ones school career. Therefore, report card grades are very important in daily educational practice. In this study, report card grades were the only dependent variable, and future research can include other measures of performance, such as scores on standardized tests, or vertically equated scores, to investigate whether the decreasing performance level can be replicated with other performance measures. This may be useful, since report card grades are influenced by different factors such as ability, motivation and effort of a student, but also the curriculum and the way the subject content was tested and graded. It was beyond the scope of the present paper to disentangle the various factors that influence report card grades. Moreover, it may be interesting to replicate the results with different performance measures such as vertically equated scores, as these scores are specifically meant to map ability differences between grades.

Our study sample constitutes a cross section of the Dutch secondary school population. We do not expect differential effects of socio-economic background and living area (rural or urban) on the observed performance decline, but we were unable to test this with the data provided by the schools. In future research, these variables could be explicitly tested to rule out that these factors affect the performance decline.

The present study focused on the performance of students in lower secondary education, as this period seems especially relevant for a decline in performance. In future studies, it would be worthwhile to include older adolescents. According to the motivation literature, motivation seems to decline in early adolescence but appears to rebound in middle adolescence. The motivation literature does show a slight increase in motivation around the age of 16 (e.g. Gottfried et al. 2001), and it would be interesting to investigate whether this would translate into increasing student performance during the second half of secondary education.

Acknowledgments This research was funded by the Dutch ministry of Education, Culture, and Science. We thank the schools, teachers and students who provided data for this study.

Open Access This article is distributed under the terms of the Creative Commons Attribution 4.0 International License (http://creativecommons.org/licenses/by/4.0/), which permits unrestricted use, distribution, and reproduction in any medium, provided you give appropriate credit to the original author(s) and the source, provide a link to the Creative Commons license, and indicate if changes were made.

\section{References}

Anderman, E. M., \& Maehr, M. L. (1994). Motivation and schooling in the middle grades. Review of Educational Research, 64, 287-309. doi:10.3102/00346543064002287.

Boekaerts, M., \& Corno, L. (2005). Self-regulation in the classroom: a perspective on assessment and intervention. Applied Psychology: An International Review, 54, 199-231. doi:10.1111/j.1464-0597.2005.00205.x.

Boekaerts, M., van Nuland, H., \& Martens, R. L. (2010). Perspectives on motivation: what mechanisms energise students's behavior in the classroom? In K. Littleton, C. Wood, \& J. Kleine Staarman (Eds.), International handbook of psychology in education (pp. 535-569). Bigley: Emerald Group Publishing Limited.

Cardelle-Elawar, M. (1992). Effects of teaching metacognitive skills to students with low mathematics ability. Teaching and Teacher Education, 8, 109-121. doi:10.1016/0742-051X(92)90002-K.

Chouinard, R., \& Roy, N. (2008). Changes in high-school students' competence beliefs, utility value and achievement goals in mathematics. British Journal of Educational Psychology, 78, 31-50. doi:10.1348/ 000709907 X197993.

Cornoldi, C., Carretti, B., Drusi, S., \& Tencati, C. (2015). Improving problem solving in primary school students: the effect of a training programme focusing on metacognition and working memory. British Journal of Educational Psychology, 85, 424 439. doi:10.1111/bjep.12083. 
Duckworth, A. L., \& Seligman, M. E. P. (2005). Self-discipline outdoes IQ in predicting academic performance of adolescents. Psychological Science, 16, 939-944. doi:10.1111/j.1467-9280.2005.01641.x.

Dutch Inspectorate of Education. (2014). The state of education in the Netherlands 2012/2013. (De staat van het onderwijs: onderwijsverslag 2012/2013). Utrecht: The Dutch Inspectorate of Education.

Eccles, J. S. (1987). Gender roles and women's achievement-related decisions. Psychology of Women Quarterly, 11, 135-172. doi:10.1111/j.1471-6402.1987.tb00781.x.

Eccles, J. S., Lord, S., \& Midgley, C. (1991). What are we doing to early adolescents? The impact of educational contexts on early adolescents. American Journal of Education, 99, 521-542.

Eccles, J. S., Midgley, C., Wigfield, A., Buchanan, C. M., Reuman, D., Flanagan, C., \& Mac Iver, D. (1993). Development during adolescence: the impact of stage-environment fit on young adolescents' experiences in schools and families. American Psychologist, 48(2), 90-101. doi:10.1037/0003-066X.48.2.90.

Fernandez-Duque, D., Baird, J. A., \& Posner, M. I. (2000). Executive attention and metacognitive regulation. Consciousness and Cognition, 9, 288-307. doi:10.1006/ccog.2000.0447.

Fischer, F., Schult, J., \& Hell, B. (2013). Sex differences in secondary school success: why female students perform better. European Journal of Psychology of Education, 28, 529-543. doi:10.1007/s10212-012-0127-4.

Gillet, N., Vallerand, R. J., \& Lafrenière, M. K. (2012). Intrinsic and extrinsic school motivation as function of age: the mediating role of autonomy support. Social Psychology of Education: An International Journal, 15, 77-95. doi:10.1007/s11218-011-9170-2.

Gottfried, A. E., Fleming, J. S., \& Gottfried, A. W. (2001). Continuity of academic intrinsic motivation from childhood through late adolescence: a longitudinal study. Journal of Educational Psychology, 93, 3-13. doi: 10.1037//0022-0663.93.1.

Gottfried, A. E., Marcoulides, G. A., Gottfried, A. W., Oliver, P. H., \& Guerin, D. W. (2007). Multivariate latent change modeling of developmental decline in academic intrinsic math motivation and achievement: childhood through adolescence. International Journal of Behavioral Development, 31, 317-327. doi:10. $1177 / 0165025407077752$.

Guay, F., \& Vallerand, R. J. (1997). Social context, student's motivation, and academic achievement: toward a process model. Social Psychology of Education, 1, 211-233. doi:10.1007/BF02339891.

Hill, J. P., \& Lynch, M. E. (1983). The intensification of gender-related role expectations during early adolescence. In J. Brooks-Gunn \& A. Petersen (Eds.), Girls at puberty: Biological and psychosocial perspectives (pp. 201-228). New York: Plenum.

Hox, J. J. (2010). Multilevel analysis; Techniques and applications (2nd ed.). Routledge: New York.

Hulleman, C. S., Godes, O., Hendricks, B. L., \& Harackiewicz, J. M. (2010). Enhancing interest and performance with a utility value intervention. Journal of Educational Psychology, 102, 880-895. doi:10.1037/a0019506.

Jacobs, J. E., Lanza, S., Wayne Osgood, D., Eccles, J. S., \& Wigfield, A. (2002). Changes in children's selfcompetence and values: gender and domain differences across grades one through twelve. Child Development, 73, 509-527. doi:10.1111/1467-8624.00421.

Juvonen, J., \& Murdock, T. B. (1995). Grade-level differences in the social value of effort: implications for selfpresentation tactics of early adolescents. Child Development, 66, 1694-1705. doi:10.1111/j.1467-8624.1995. tb00959.x.

Krathwohl. (2010). A revision of Bloom's taxonomy: an overview. Theory Into Practice, 41, 212-218. doi:10. 1207/s15430421tip4104_2.

Mok, M. M. C., McInerney, D. M., Zhu, J., \& Or, A. (2014). Growth trajectories of mathematics achievement: longitudinal tracking of student academic progress. British Journal of Educational Psychology, 85, 154-171. doi:10.1111/bjep. 12060 .

Peetsma, T., \& van der Veen, I. (2011). Relations between the development of future time perspective in three life domains, investment in learning, and academic achievement. Learning and Instruction, 21, 481-494. doi:10. 1016/j.learninstruc.2010.08.001.

Peetsma, T., Hascher, T., van der Veen, I., \& Roede, E. (2005). Relations between adolescents' self-evaluations, time perspectives, motivation for school and their achievement in different countries and at different ages. European Journal of Psychology of Education, 10, 209-225. doi:10.1007/BF03173553.

Pintrich, P. R., \& de Groot, E. V. (1990). Motivational and self-regulated learning components of classroom academic performance. Journal of Educational Psychology, 82(1), 33-40. doi:10.1037/0022-0663.82.1.33.

Robbins, S. B., Le, H., Davis, D., Lauver, K., Langley, R., \& Carlstrom, A. (2004). Do psychosocial and study skill factors predict college outcomes? A meta-analysis. Psychological Bulletin, 130, 261-288. doi:10.1037/ 0033-2909.130.2.261.

Shim, S. S., Ryan, A. M., \& Anderson, C. J. (2008). Achievement goals and achievement during early adolescence: examining time-varying predictor and outcome variables in growth-curve analysis. Journal of Educational Psychology, 100, 655-671. doi:10.1037/0022-0663.100.3.655.

Snijders, T. A. B., \& Bosker, R. J. (2012). Multilevel analysis: An introduction to basic and advanced multilevel modeling (2nd ed.). London: Sage Publishers. 
Steinberg, L. (2005). Cognitive and affective development in adolescence. Trends in Cognitive Science, 9, 69-74. doi:10.1016/j.tics.2004.12.005.

van der Stel, M., \& Veenman, M. V. J. (2010). Development of metacognitive skillfulness: a longitudinal study. Learning and Individual Differences, 20, 220-224. doi:10.1016/j.lindif.2009.11.005.

van Houtte, M. (2004). Why boys achieve less at school than girls: the difference between boys' and girls' academic culture. Educational Studies, 30, 159-173. doi:10.1080/0305569032000159804.

Veenstra, R. (1999). Students - classes - schools. Achievement of students in secondary education [Leerlingen klassen - scholen. Prestaties en vorderingen van leerlingen in het voortgezet onderwijs] (Doctoral thesis, University of Groningen, Groningen, the Netherlands). Retrieved from http://ics.uda.ub.rug.nl/root/ Dissertations/1999/VeenstraR/?pLanguage=en\&pFullItemRecord=ON.

Watt, H. M. G. (2004). Development of adolescents' self-perceptions, values, and task perceptions according to gender and domain in 7th- through 11th-grade Australian students. Child Development, 75, 1556-1574. doi: 10.1111/j.1467-8624.2004.00757.x.

Wigfield, A., \& Wagner, A. L. (2005). Competence, motivation, and identity development during adolescence. In A. J. Elliot \& C. S. Dweck (Eds.), Handbook of competence and motivation (pp. 222-239). New York: Guilford Press.

Lindy A. Wijsman MSc. Institute of Psychology, Unit Developmental and Educational Psychology, Leiden University, Wassenaarseweg 62A, 2333 AL Leiden, Netherlands. Tel.: 003171527 1708; E-mail: 1.a.wijsman@fsw.leidenuniv.nl

Current themes of research:

Motivation and Achievement of Secondary School Students. Talent Development.

Most relevant publications:

Wijsman, L., Mainhard, T., \& Brekelmans, M. (2014). Stimulating autonomous motivation in the classroom. In D. Zandvliet, P. den Brok, T. Mainhard \& J. van Tartwijk (Eds.), Interpersonal relationships in education: From theory to practice (pp. 231-249). the Netherlands: Sense publishers.

Wubbels, Th., Brekelmans, J. M. G., den Brok, P. J., Wijsman, L., Mainhard, T., \& van Tartwijk, J. W. F. (2014). Teacher-student relationships and classroom management. In E. T. Emmer \& E. Sarbonie (Eds.), Handbook of classroom management (2nd edition). Lonon: Taylor \& Francis.

Dr. Matthijs J. Warrens. GION, University of Groningen, Grote Rozenstraat 3, 9712 TG Groningen, Netherlands. Tel.: 003150363 6691; E-mail: m.j.warrens@rug.nl

Current themes of research:

Agreement measures. Association coefficients. Statistics.

Most relevant publications:

Dr. Nadira Saab. ICLON, Leiden University, Wassenaarseweg 62A, 2333 AL Leiden, Netherlands. Tel.: 0031 71527 5726; E-mail: n.saab@iclon.leidenuniv.nl

Current themes of Research:

Impact of powerful and innovative learning methods on learning processes and learning results, such as collaborative learning, computer assisted learning, assessment and motivation.

Most relevant publications:

Saab, N., \& Stengs, S. (2014). Teachers who use Flipping the Classroom: professional development, feelings of autonomy and TPACK. International Journal of Social Media and Interactive Learning Environments, 2(4), 341-360.

Saab, N., Van Joolingen, W. R., \& Van Hout-Wolters, B. H. A. M. (2012). Support of the collaborative inquiry learning process: influence of support on task and team regulation. Metacognition and Learning, 7, 7-23. 
Anjewierden, A., Gijlers, H., Kolloffel, B., Saab, N., \& De Hoog, R. (2011). Examining the relation between domain-related communication and collaborative inquiry learning. Computers and Education, 57,1741-1748.

Gijlers, H., Saab, N., Van Joolingen, W. R., De Jong, T., \& Van Hout-Wolters, B. H. A. M. (2009). Interaction between tool and talk: how instruction and tools support consensus building in collaborative inquiry-learning environments. Journal of Computer Assisted Learning, 25 (3), 252-267.

Saab, N., Van Joolingen, W. R., \& Van Hout-Wolters, B. H. A. M. (2009). The relation of learners' motivation with the process of collaborative scientific discovery learning. Educational Studies, 35 (2), 205-222.

Prof. Dr. Jan H. van Driel. ICLON, Leiden University, Wassenaarseweg 62A, 2333 AL Leiden, Netherlands. Tel.: 003171527 4027; E-mail: driel@iclon.leidenuniv.nl; Website: http://iclon.leiden.edu/scientificresearch/staff/professors/drieljhvan.html

Current themes of research:

Teacher knowledge. Science education. Higher education.

Most relevant publications:

Verloop, N., Van Driel, J.H., \& Meijer, P. (2001). Teacher knowledge and the knowledge base of teaching. International Journal of Educational Research, 35, 5, 441-461.

Van Driel, J.H., Bulte, A.M.W., \& Verloop, N. (2007). The relationships between teachers' general beliefs about teaching and learning and their domain specific curricular beliefs. Learning and Instruction, 17, 2, 156-171.

Van Driel, J.H., \& Berry, A. (2012). Teacher professional development focusing on pedagogical content knowledge. Educational Researcher, 41, 1, 26-28.

Prof. Dr. P. Michiel Westenberg. Institute of Psychology, Unit Developmental and Educational Psychology, Leiden University, Wassenaarseweg 52, 2333 AK Leiden, Netherlands; Tel:: 003171527 3628; E-mail: Westenberg@fsw.leidenuniv.nl; Website: http://www.leiden.edu/, http://socialsciences.leiden.edu/ psychology/

\section{Current themes of research:}

1. Learning motivation and achievement (with a focus on the high school years)

2. Public speaking and social anxiety (with a focus on the high school years)

3. Presentation skills and social acceptance (with a focus on the high school years)

http://www.adolescentdevelopment-leidenuniversity.nl/

\section{Most relevant publications:}

Blöte, A. W., Miers, A. C., Heyne, D. A., \& Westenberg, P. M. (2015). Social anxiety and the school environment of adolescents. In K. Ranta, A. M. La Greca, L-J. García-Lopez, and M. Marttunen (Eds.), Social Anxiety and Phobia in Adolescents: Development, Manifestation and Intervention Strategies. Springer, USA.

Blöte, A. W., Poungjit, A., Miers, A. C., Van Beek, Y., \& Westenberg, P. M. (2015). The Speech Performance Observation Scale for Youth (SPOSY): assessing social performance characteristics related to social anxiety. Journal of Experimental Psychopathology.

Van den Bos, E., De Rooij, M., Miers, A. C., Bokhorst, C. L., \& Westenberg, P. M. (2014). Adolescents' increasing stress response to social evaluation: pubertal effects on cortisol and alpha-amylase during public speaking. Child Development, 85(1), 220-236. doi:10.1111/cdev.12118.

Heyne, D. A., Sauter, F. M., Ollendick, T. H., Van Widenfelt, B. M., \& Westenberg, P. M. (2014). Developmentally sensitive cognitive behavioral therapy for adolescent school refusal: rationale and case illustration. Clinical Child and Family Psychology Review, 17(2), 191-215. doi:10.1007/s10567-013-0160-0

Heyne, D.A., Sauter, F.M., Widenfelt, B.M., van Vermeiren, R.R.J.M., \& Westenberg, P.M. (2011). School refusal and anxiety in adolescence: non-randomized trial of a developmentally sensitive cognitive behavioral therapy. Journal of Anxiety Disorders, 25(7), 870-878. 